\title{
The reproductive health of young people in Egypt
}

\author{
Nahla G. Abdel-Tawab \\ Population Council \\ Noha Roushdy \\ Maia Sieverding \\ Population Council
}

Follow this and additional works at: https://knowledgecommons.popcouncil.org/departments_sbsr-pgy

Part of the Demography, Population, and Ecology Commons, Family, Life Course, and Society Commons, International Public Health Commons, Labor Economics Commons, Public Health Education and Promotion Commons, Social Policy Commons, and the Women's Health Commons How does access to this work benefit you? Let us know!

\section{Recommended Citation}

Abdel-Tawab, Nahla G., Noha Roushdy, and Maia Sieverding. 2012. "The reproductive health of young people in Egypt," Survey of Young People in Egypt Policy Brief no. 1. Cairo: Population Council. 


\section{Survey of Young People in Egypt Policy Brief Series}

\section{THE REPRODUCTIVE HEALTH OF YOUNG PEOPLE}

\section{IN EGYPT}

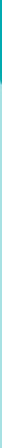

By Nahla Abdel Tawab, Noha Roushdy, and Maia Sieverding

FORDFOUNDATION Working with Visionaries on the Frontlines of Social Change Worldwide
(2) Population Council Research that makes a difference 


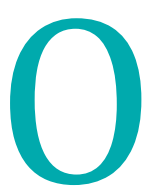
ver one third of the population in Egypt is currently between 10 and 29 years of age. The lives of this disproportionately large number of young people in Egypt are significantly different from the lives of previous generations; their needs for a safe and smooth transition to adulthood are particular to the requirements and challenges of their time.

Young people in Egypt are experiencing puberty earlier, spending more years in school, and marrying later than previous generations. Delayed marriage means a prolonged period of singlehood, particularly for young males. In fact, most young men under 29 are unmarried. Most young women are exposed to female circumcision in adolescence, and social pressure favoring early marriage and childbearing has not waned.

These aspects of young people's lives in Egypt have serious implications for their reproductive health, a topic that receives only limited attention from policymakers. Not only do the majority of unmarried youth not receive reproductive health services, their exposure to reliable information channels and support regarding issues pertaining to their physical, mental, and social well-being before marriage is low. Calls to conceal sexuality-related information from young people fail to take note of the particular susceptibility of this group to risky behaviors and unhealthy practices that affect their reproductive health and their healthy transition to adulthood.

\section{Key Messages}

- Egyptian youth receive inadequate information about puberty from parents and health professionals, so they turn to sources, such as friends and cinema, that may not be reliable.

- Although the prevalence of female circumcision has declined among younger women, support for the practice remains widespread.

- Only 3\% of youth aged 15-29 could correctly identify all possible routes of transmission for HIV/AIDS.

- The desired number of children among young people remains above the national target of 2.1 .

\section{Data and methodology}

Data for this brief are drawn from the Survey of Young People in Egypt (SYPE), which provides data collected from a nationally representative sample of young people aged 10-29 on the five key life transitions of education, work, family formation, health, and civic and political participation. ${ }^{1}$ A total of 15,029 young people $(6,949$ males and 8,080 females) from 11,372 families in both rural and urban settings, including informal housing areas, participated in this study.

The study included a special module on health and safety that covered young people's sense of their physical and mental well-being, health-related practices and habits, and access to health care services and health-related education and information. Questions on sexual and reproductive health included such topics as menarche, relationships, female circumcision, HIV/AIDS, marriage and childbearing, contraception, and sources of knowledge and parental guidance on these issues.

\section{Talking with parents about puberty}

SYPE revealed that parents either do not talk with their children about puberty and conception, are late in providing the needed information, or offer insufficient information to their children about reproductive issues.

According to SYPE, the majority of girls in Egypt $(67 \%)$ were shocked, cried, or felt afraid as a reaction to menarche. Another $10 \%$ of female respondents did not know what to do. Failure to know what to do upon menarche was particularly prevalent among girls in Upper Egypt. While the average age of menarche in Egypt is 12.8 years, only $24 \%$ of girls aged 10-14 surveyed in SYPE had talked with a parent about puberty.

In regard to boys, the situation is even more alarming. While nearly half of female respondents aged 10-29 (43\%) stated that they had talked with a parent about pubertal changes, only 7\% of males aged 10-29 had.

Young people's expressed need for reproductive health information has been reiterated by numerous studies. A study in 2008 to assess the performance of youth-friendly clinics in nine teaching hospitals in Egypt noted that all interviewed staff found that "youth are in need of sound reproductive health information from respectable, trustworthy persons" and that "this need cannot be met by parents, who feel embarrassed to discuss such topics, or friends, whose information credibility cannot be guaranteed" (Oraby et al. 2008). A study on preparatory schools conducted in 2000 noted that $70 \%$ of the medical

\footnotetext{
${ }^{1}$ SYPE was conducted in cooperation with the Egyptian Cabinet's Information and Decision Support Center (IDSC) and funded by multiple donors.
} 
personnel in schools were regularly being sought out by students with queries regarding their reproductive health (El Tawila 2000).

\section{Sources of information on puberty available to young people}

As a result of parents' failure to satisfy their children's need to talk about puberty, friends and acquaintances make up the source of information on puberty for more than half $(57 \%)$ of young males aged 10-29, followed by film/cinema (18\%). In fact, more respondents cited films and cinema as source of information than the school, which was identified by only $12 \%$ of males and $4 \%$ of females.

Figure 1: Source of information on puberty, by gender, youth age 10 - 29

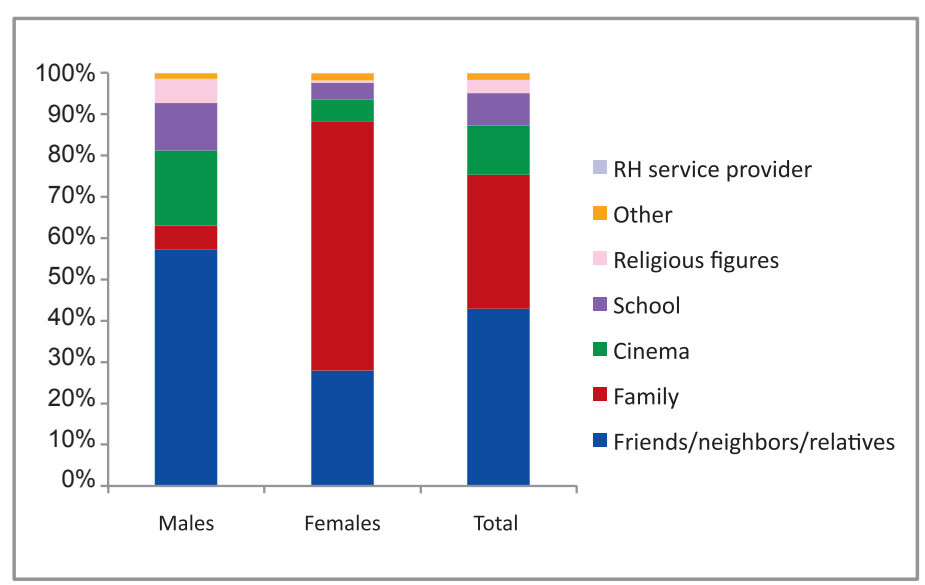

Furthermore, less than $1 \%$ of respondents cited a reproductive health service provider as their source of information on pubertal changes, and only a limited number of males (less than 5\%) and a negligible number of females cited a religious authority as their source of information. The absent role of medical personnel in providing information to young people on reproductive health reflects the medical culture in Egypt, which denies young people reproductive health services. It also emphasizes the need to expand and intensify existing initiatives. The same is true with respect to contraception. Six percent of young people aged 15-29 stated that they did not have any source of information on contraception, while the majority $(79 \%)$ identified radio and television as their major source. Only onequarter of respondents identified health care providers as their source of information on contraception.

In the absence of a comprehensive system providing young people with information on the physiological and psychological changes that occur during puberty and other reproductive health information, around $44 \%$ of respondents aged 15-29 found the information they received insufficient. Males (47\%), those aged 15-17
(50\%), and youth living in Urban Governorates (56\%) were particularly likely to say that they did not receive sufficient information about puberty.

\section{Perception of circumcision}

SYPE found that three quarters of female Egyptian youth aged 10-29 are circumcised. The overall mean age at circumcision at present is 9.5 years, a few years earlier than the average age at menarche.

SYPE also demonstrated that the prevalence of circumcision decreases with younger age; while $90 \%$ of young women aged 24-29 were circumcised, circumcision was reported among $79 \%$ of female youth aged 15-17. It is unlikely that these youth are awaiting circumcision, as they have passed the typical age for the procedure. SYPE confirmed that the prevalence of circumcision is highest in Upper Egypt (85\%) and lowest in the frontier governorates (52\%) and the urban governorates (54\%). Wealth is another determinant of the prevalence of female circumcision, as it is least frequent among females in the highest wealth quintile $(50 \%)$.

These findings agree with the 2008 Egyptian Demographic and Health Survey (EDHS), which suggested similar trends in the practice. According to the EDHS, $91 \%$ of all female youth aged 15-49 are circumcised. Considering the decreased prevalence among young women, the 2008 DHS suggested that "adherence to the practice might be declining in some population groups" (El-Zanaty and Way 2009).

Figure 2: Prevalence of female circumcision, by region and age group (percent)

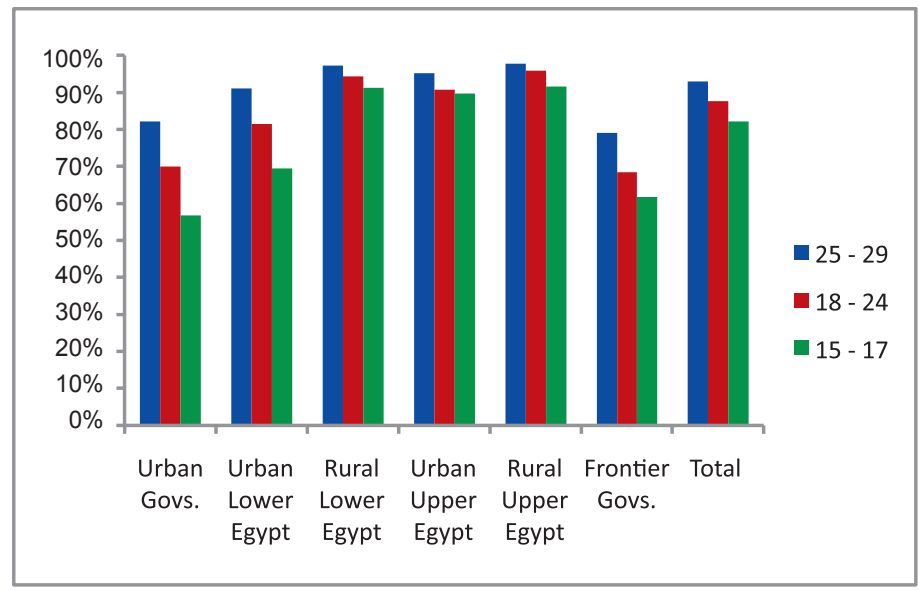

If the prevalence of female circumcision seems to be diminishing in some population groups, support for the practice among young people is alarmingly resilient. The majority of young people surveyed in SYPE (64\%) think circumcision is necessary. However, there is a gender difference in support for the practice: $70 \%$ of male youth 
said that the practice was necessary, compared to $58 \%$ of female youth. Support for female circumcision was stronger among youth living in rural areas $179 \%$ of rural males said female circumcision was necessary, compared to $56 \%$ of urban males).

Age is associated with young people's perception of female circumcision: $60 \%$ of male youth aged 15-17 said the practice was necessary, compared to $78 \%$ of those aged 25-29. The corresponding figures for female youth were $52 \%$ and $64 \%$, respectively. Younger youth were also considerably more likely to say that they "do not know" whether the practice is necessary. Although higher educational attainment was associated with less support for female circumcision among female respondents, education had little association with male respondents' perception of female circumcision. While 41\% percent of female respondents with a universitylevel education or above said the procedure was necessary, $69 \%$ percent of male respondents of the same educational level did. Surprisingly, findings indicate that the perception that female circumcision is necessary is more prevalent among these highly educated male youth than among their uneducated peers $(63 \%)$.

Figure 3: Percent of youth age 15-29 who think female circumcision is necessary, by gender and education

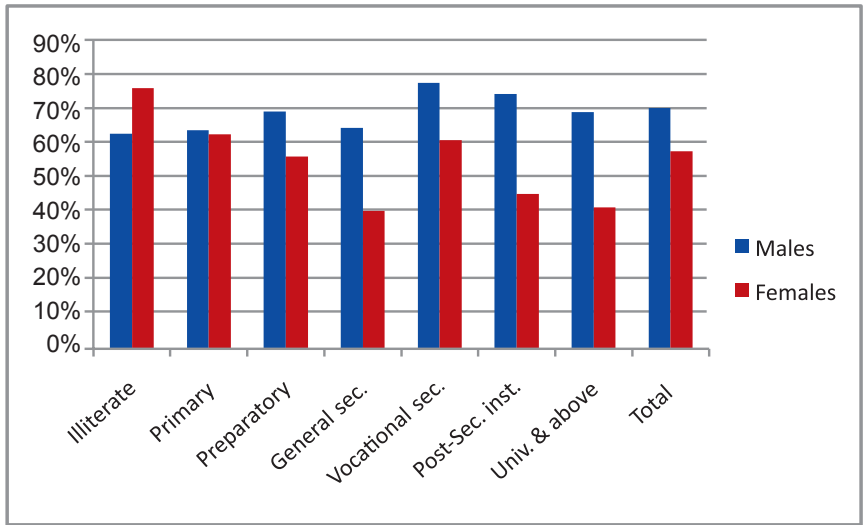

These figures substantiate the findings of a qualitative study in two rural communities in Upper Egypt and a large slum area in Cairo in 2008-2009 on the perception of female sexuality and its effect on persistent support for female circumcision. The study found that male support for the practice was widespread within the study group. It noted that support is particularly widespread among young men, whose exposure to sexually explicit media "strengthened the belief that lack of FGM/C would lead women to be promiscuous due to excessive sexuality" (Fahmy et al. 2010).

\section{The medicalization of female circumcision}

SYPE found that medical personnel are responsible for the circumcision of over half of all circumcised females in Egypt (57\%). Circumcision is performed by a doctor in over half of circumcisions in the urban governorates and in Lower Egypt. Even though circumcision often takes place in the girl's or someone else's home, about a third of circumcisions $(34 \%)$ take place in a private clinic.

Comparing SYPE findings to the 2008 EDHS, which surveyed women aged $15-49$, it becomes clear that the medicalization of female circumcision is a recent development. Among the older population of respondents in the EDHS, only 24\% had been circumcised by a medical doctor (El-Zanaty and Way 2009).

\section{Knowledge of HIV/AIDS}

Young people's knowledge of HIV/AIDS, the most publicly addressed sexually transmitted infection (STI), is alarmingly limited. Even though the majority of respondents over 15 years of age have heard of HIV/AIDS, only 3\% could identify all possible routes of transmission. Most respondents relied on the media (89\%) as a source of information on HIV/AIDS, whereas $26 \%$ gave the school as their source of information and $13 \%$ friends. SYPE results on accurate knowledge of HIV/AIDS reiterate the findings of the 2008 EDHS, which indicated that only $3 \%$ of those aged $15-19$ and $6 \%$ of those aged $20-24$ have comprehensive knowledge of HIV/AIDS (ElZanaty and Way 2009).

Discrimination against people living with HIV is prevalent. Only $21 \%$ of SYPE respondents aged 15 29 were willing to interact with someone living with HIV/AIDS. Among young people with university education and above, the group that showed the least negative attitudes toward persons living with HIV/ AIDS, this figure still reached only 33\%.

Although knowledge of other STIs was not included in the SYPE questionnaire, a number of other studies indicate that young people in Egypt lack information on STIs and their modes of transmission. The 2008 EDHS indicated that four out of every 10 married women in Egypt were not familiar with STIs (ElZanaty and Way 2009). A baseline survey conducted by Care Egypt's Youth's Rights for Risk Reduction Program to assess young people's awareness of HIV/ AIDS and other sexually transmitted infections in Beni-Sueif and Qena found that "less than one fifth 
of the sample had any knowledge about syphilis, chlamydia, gonorrhea, and the hepatitis virus" (Heida 2006).

\section{Relationships}

The lack of awareness among young people of sexually transmitted infections and their modes of transmission is particularly worrying given the extended period of singlehood among young people in Egypt.

Nearly a quarter (24\%) of SYPE respondents aged 15-29 stated that they knew girls their age in relationships with boys, and about one-fifth of respondents (21\%) stated that they knew boys their age in relationships with girls. SYPE findings showed that young people living in urban areas, in the highest wealth quintile, and those aged 18 and above were more likely to report the occurrence of such relationships. Although such findings may suggest that relationships are more common among youth with these characteristics, it is highly possible that in different settings young people are less inclined to disclose such information to a stranger, particularly in close proximity to parents.

However, SYPE findings are supported by earlier studies on relationships amongyoung people in Egypt. A study conducted by the Cairo Demographic Center in 2007 on young people aged 18-29 in six Egyptian governorates found that $18 \%$ of females and 19\% of males knew of others within their social network who engaged in premarital sexual relationships. The same study showed a high likelihood that young people are engaged in sexual relationships with multiple partners prior to marriage, as only $12 \%$ of males and $19 \%$ of females mentioned that such sexual relationships take place among couples in a committed relationship (Nawar et al. 2006).

\section{Marriage and Childbearing}

Among SYPE respondents, $41 \%$ of female youth and $13 \%$ of male youth were ever-married. Almost a quarter of ever-married females married before reaching 18.

Adolescent pregnancy remains a concern in Egypt. Although rates in urban governorates are stabilizing, adolescent pregnancy is a consistent problem on a sub-regional level; early marriage and childbearing tend to be concentrated in certain communities. SYPE findings show that $4 \%$ of girls aged 15-19 had ever been pregnant at the time of the study, and that adolescent pregnancy is highest among illiterate women (13\%), in informal urban areas $(7 \%)$ and among those in the frontier governorates and in rural Upper Egypt (5\%). Among married females aged 15-17, more than half did not make the decision to marry on their own.

SYPE findings indicate a decreasing rate of adolescent pregnancy, at 4\% among 15-19 year-old females, as compared to the 2008 EDHS, which estimated a national level of 10\% among 15-19-year-old females (El-Zanaty and Way 2009).

SYPE findings suggest that older married females are more likely to use some form of contraception than young females aged 15-17. Only $26 \%$ of married female youth aged $15-17$, compared to $59 \%$ of those aged 18-24, were using contraception at the time of the interview.

\section{Preferred number of children among young people}

SYPE reveals that among young people in Egypt, the desired number of children is above the national rate of 2.1, at 2.7 among unmarried youth and 2.8 among married youth. These findings suggest that young people may not be sufficiently or effectively targeted by family planning messages. In effect, even the lower desired number of children among unmarried youth remains higher than the desired rates documented in 2005 and 1995. Even among married and unmarried female youth with a university-level education, the desired number of children is 2.6 and 2.5 respectively.

Figure 4: Desired number of children among unmarried and married female youth aged 15-29

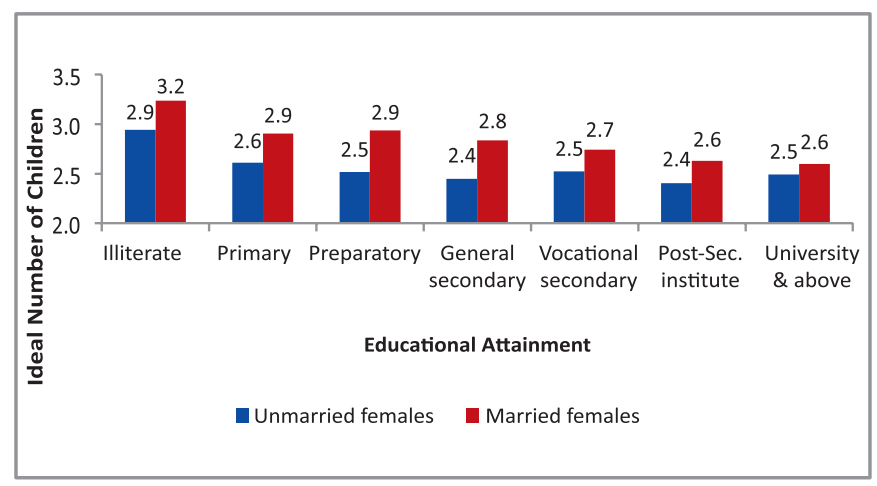

\section{Policy Recommendations}

The SYPE results call for action to integrate adolescent and youth reproductive health in the national strategy on youth and youth health. They underscore the need for:

- The assessment of state and civil society initiatives that transmit reproductive health 
information to young people and offer counseling and other reproductive health services, such as school curricula and pre-marital counseling services offered by the Ministry of Health.

- A national, comprehensive, age-appropriate reproductive health module to be integrated in the educational program of primary, preparatory, and secondary school students. At present, Algeria, Bahrain, Jordan, Morocco, and Tunisia have integrated reproductive health education in their national curricula (De Jong et al. 2007).

- Legislation that assists civil society organizations in disseminating reproductive health information to school youth.

- A national campaign on HIV/AIDS and other sexually transmitted infections that targets young people of reproductive age, including unmarried youth. It should be gender-sensitive and address young people from all socioeconomic backgrounds.

- The integration of female circumcision into a broader approach to youth reproductive health and bodily rights. This approach needs to consider both the demand and supply sides of female circumcision. On the supply side, there is a need to discourage the involvement of medical personnel in perpetuating the practice, through education, training, and enforcement of punitive legislation. On the demand side, campaigns need to target parents to convey the message that female circumcision is a violation of girls' bodily rights and integrity regardless of who performs the procedure.

- Specialized reproductive health services for married adolescent girls that ensure their access to family planning and counseling services.

- Further research on sexuality and reproductive health among youth in Egypt. SYPE findings call for immediate action on the part of the designated authorities to facilitate research on youth sexual behavior, including sexual practices, 'urfi marriage and other relationship forms, and sexual harassment.

\section{References}

De Jong, Jocelyn, et al. 2007. Young People's Sexual and Reproductive Health in the Middle East and North Africa. Washington, D.C.: Population Reference Bureau.

El Tawila, Sahar, et al. 2000. The School Environment in Egypt: A Situation Analysis of Public Preparatory Schools. New York: The Population Council.

El-Zanaty, Fatma and Ann Way. 2009. Egypt Demographic and Health Survey 2008. Cairo: Egypt Ministry of Health and Population and Egypt National Population Council.

Fahmy, Amel, Mawaheb T. El Mouelhy and Ahmed R. Ragab. 2010. "Female Genital Mutilation/ Cutting and Issues of Sexuality in Egypt." Reproductive Health Matters 18 (36): 181-190.

Heida, Zeinab. 2006. Youth Rights for Risk Reduction. Unpublished study. Cairo: Care International.

Nawar, Laila, Magdi Abdel-Qader and Abd el-Ghani Mohamed. 2006. Awda' wa Itijahat al-Shabab fi Misr. Cairo: Cairo Demographic Center.

Oraby, Doaa, et al. 2008. Assessment of Youth Friendly Clinics in Teaching Hospitals in Egypt. Cairo: Family Health International and UNFPA.

The Population Council confronts critical health and development issues-from stopping the spread of HIV to improving reproductive health and ensuring that young people lead full and productive lives. Through biomedical, social science, and public health research in 50 countries, we work with our partners to deliver solutions that lead to more effective policies, programs, and technologies that improve lives around the world. Established in 1952 and headquartered in New York, the Council is a nongovernmental, nonprofit organization governed by an international board of trustees.

\section{www.popcouncil.org}

